\title{
About time: gender equality in Malta's working-time regime?
}

\section{Frances Camilleri-Cassar}

Faculty of Laws, University of Malta

E-mail: frances.camilleri-cassar@um.edu.mt

To what extent does Malta's social policy support gender equality, in the use of time? How much do state policies assume that men and women both need time to care, as well as for paid work? Does Malta's full-time paid work structure allow time for the equal sharing of unpaid care responsibilities between women and men, that in turn enhances gender equity in the workplace and domestic sphere? Themes that emerge in the study rest largely on women's voices. The study finds that women need to shift their full-time economic activity to shorter and flexible working hours when they become mothers, with negative consequences of loss in income and career regression. Labour market exit and financial dependence on men is also a frequent occurrence. The findings of the study suggest that strong pressure to assume traditional roles is embedded not only in Maltese culture and social norms, but also in the state's own social policy.

Keywords: social policy, gender equality, working-time regimes, parenthood, employment.

\section{Introduction}

This article seeks to contribute to a well-established literature on working-time regimes, and the gendered forces behind women's lives. It focuses largely on Malta's culture of long working hours and traditional expectations, which suggest incompatibility with the promotion of gender equality. Although long hours and the traditional gender arrangement have long impacted negatively on women's labour market participation, the phenomenon is a rarely studied aspect of working-time regimes. The approach adopted in the study, and its methodology, give a voice to Maltese women and their current existing realties through eliciting data from in-depth interviews. This approach may well be innovative within the context of literature on working-time regimes and working-time arrangements. The study also discusses policy implications and recommendations for gender equality that may well be of relevance to policymakers in Malta.

The key research questions are: To what extent does Malta's social policy support gender equality in the use of time? Do Malta's working-time patterns help strengthen or change the traditional gender arrangement? This study adopts a gender-based workingtime regime approach as a conceptual framework. We cannot rely on common assumptions about time and unpaid care work. What matters is whether state policies are effective enough to promote gender equality in terms of whose time is being used for familial responsibilities, and an understanding of a culture of long working hours around the discourse of gender equality. The wider literature suggests that divergent working-time patterns are often linked with the institutional and regulatory environment 
in which they operate (see Jacobs and Gerson, 2004). For example, Figart and Mutari (2000) suggest that countries with shorter working hours tend to have a narrower gender gap in labour market participation and higher levels of gender equality. The authors claim that 'gender equity is generally higher in European countries that have concentrated on reductions in the standard work week rather than increasing flexibility' (Figart and Mutari, 2000: 848).

The study's contribution to the literature focuses on Malta's working-time regime, the legal regulations regarding hours of paid work and the gendered forces behind women's lives as a resource in the gender model. This is done through an understanding of the distribution and meaning of time to mothers in the current allocation of time between paid and unpaid work, and the constraints affecting these. I argue that while men's employment is largely undisturbed by their transition into fatherhood, women's labour market decisions are negatively impacted when they become mothers. The first question that concerns this study is the extent to which a shorter working week may promote gender equality in the division of paid and unpaid work. I then go on to discuss women's preferences for paid work, and the time constraints around family obligations.

\section{A shorter working week?}

A reduction in working hours is high on the political agenda of the European Union (EU) and its member states, and time famine debates are a topical issue. Moreover, with its key priority of job creation and employment growth, the European Commission signals the gradual decline in the standard working week, the standard contract and the standard career with a lifetime job. The Employment Options Survey 1998 reveals that employed men are more likely to want to reduce their hours of work than are employed women. Conversely, women are more likely to be under-employed and to want to increase their hours. A key influence on women's working-time preferences is motherhood. An analysis of the survey further shows that while fatherhood has little influence on men's preferred working hours, women with young children are more likely to prefer either short full-time or substantial part-time hours. Indeed, mothers of young children are more likely to work part-time or shorter full-time hours, compared with childless women (Fagan and Warren, 2001).

While it is difficult for individual negotiations to convert preferences into actual working time, collective action by the social partners may, indeed, broaden the politics of time (Fagan and Warren, 2001). For example, policies to reduce working time are characteristic of the French socio-political environment, and the state in France has intervened to regulate a reduction in full-time hours. Pascall (2012) points out that the implementation of the Aubry laws, led to the spread of a thirty-five-hour week throughout French firms and families. Fagnani and Letablier (2006) concur that the thirty-five-hour week law has made the work-life balance much easier.

As a result of state policies and collective bargaining in the Netherlands, full-time hours are falling, alongside an expansion in part-time work (Fagan and Warren, 2001). The core concept of the Dutch 'combination model' is that 'both paid and unpaid work are equally valued' (Plantenga, 2002: 54). The model is based on the principle of a thirty-two-hour week, which favours the combination of a part-time wage, with part-time homemaking, for both parents. Despite criticism that the combination model has affected women's rather than men's labour market participation, policies around the model were 
instrumental in pulling away from the system of the traditional male breadwinner regime (Pascall, 2012).

Sweden makes time for parents to care through reducing parents' working hours, while they have young children, through supporting the dual-earner model and sustaining continuity in women's working lives (Pascall, 2012). In a study of innovative social policies for gender equality at work, Fox et al. (2006: vii) conclude that the three strategies towards more equal working time are: Sweden's policies to make women's working lives more like men's through (nearly) full-time employment; the Netherlands' Combination Scenario, using quality part-time employment to make men's lives more like women's; and France's shorter working week, bringing about the most gender-equal working time in Western Europe, with few part-timers.

The Danish example serves to address the earnings differential that is kept low by the standard thirty-seven-hour full-time week, and the collectively agreed limits on working time. Moreover, the tighter regulations of the Danish working-time regime has meant that the degree of gender inequality in the labour market is low. Warren (2000: 363) argues that the decline of the male-breadwinner model is linked inextricably to this issue of general labour market equality and not just to the more comprehensive policies that aim specifically to reduce inequalities in the work patterns of women and men'.

Gender is central to an analysis of time, largely because of women's time as carers that falls outside the commodified time systems operating in the workplace (Pillinger, 2000: 327). For example, in its fifth European Working Conditions survey, the European Foundation for Living and Working Conditions shows significant gender differences in terms of time spent caring for children, elderly and disabled relatives and on household chores (Eurofound, 2012a). It is also argued that some of the gender differences in working conditions have to do with the broader pattern of gender relations and inequality in society, such as women's 'double shift' of paid and unpaid work, since they do more of the care work in the home (Fagan and Burchell, 2002).

\section{Working time in Malta}

The challenge of working-time regimes has entered mainstream thinking on policy and planning in Europe, as 'the lives of many have been depicted as time poor, time squeezed, time rushed and hurried' (Warren, 2014: 14). For instance, one of the main objectives of the Europe 2020 strategy is to implement policy measures that favour a better worklife balance, in particular the EU Working Time Directive 2003/88/EC of the European Parliament and of the Council of Europe 4 November 2003 concerning certain aspects of the organisation of working time. Indeed, European work policies increasingly support the notion that men and women should both be able to engage equally in economic activity and private life. Plantenga and Hansen (2001: 292) signal that 'differences in working time between men and women arise primarily from the unequal division of unpaid work, but the extent and form that those differences take in the labour market are moderated or mediated by national working-time regimes'. Also based on the fifth European Working Conditions Survey, the European Foundation for Living and Working Conditions finds that almost 40 per cent of employees indicate that they would like to change their current working time, with a preference among men and women for shorter full-time hours (Eurofound, 2012b). 
However, while collective action for regulating a shorter working week is taking place in some societies, long and rigid full-time hours remain a coveted and protected system of earning in Malta. Full-time employment and maximum hours for part-time work vary according to economic sector. These are established in Wage Regulation Orders that regulate such sectors according to their activity of work. ${ }^{1}$ Generally, hours of work, excluding overtime, do not exceed a maximum average of forty-eight hours a week. However, an employee on a forty-hour week may be asked to work more than eight hours overtime in a particular week. Legally mandated norms may not always preclude the tendency for people to do it their own way in Malta.

Other than basic conditions of employment and the national minimum wage established by law, wages and all other working conditions are determined through bipartite, enterprise-based collective bargaining. Legislation merely establishes the minimum conditions of employment when there is no collective agreement or trade union representing the majority of employees. Contrary to practice in much of the EU, there is no significant demand in Malta for sectoral bargaining. Both employers' associations and trade unions vigorously defend enterprise-based collective bargaining. Enterprisespecific agreements are perceived as more flexible in facilitating an increase in wages and improvement in working conditions (Baldacchino, 2009: 13).

Interestingly, the only EU Directive that caused disquiet in Malta was the Working Time Directive (Baldacchino, 2009). Indeed, Malta is one of the few EU member states that opted out of Article 6 of the Working Time Directive, which limits the average working week, including overtime, to forty-eight hours. The initiative taken by the European Parliament to repeal the opt-out clause in May 2005 was a matter of considerable disagreement among Malta's social partners: employers, leading trade unions and the state (Baldacchino, 2009). Much of the concern, however, was not attributed to gender equality but to fears of a reduction in working hours and subsequent loss of income. Consequently, Malta was granted a transitional period, conditioned by the expiration of existing collective agreements. Arguably, opting out of the EU's Working Time Directive penalises anyone who takes responsibility for care (Pascall, 2012).

I am in no way suggesting that the implementation of the Directive is crucial to making the Maltese working-time regime more family-friendly and gender equal, or that the norms promoted by the Working Time Directive could provide an important source of improvement to the range of working-time options. The thrust of my argument is that the Directive is a bone of contention, not so much for gender equality but for fear of a shorter working week. Clearly, Malta's social partners support the culture of long working hours, irrespective of the implications for gender relations. Family-friendly policy is limited to substantive adjustment by women to a forty-hour, five-day week male model of work. While 'a key objective of working time policy is its potential to redistribute work in favour of women's time frames' (Pillinger, 2000: 332), regulation of working time was never concerned with the promotion of gender equality (Lehndorff et al., 2007). 'On the contrary, managing and regulating working time has been a decisive factor in reproducing gendered forms of work organization' (Zbyszewska, 2013: 31).

Parallel to the norm of working long hours and national regulatory regime is the insufficiency of public infrastructure for the provision of care. Even when governments recognised the need for the provision of childcare, Malta has little experience of high quality publicly supported care services. In a study by Malta's Ministry of Education, Youth and Employment, Sollars et al. (2006) point to disparate practices of varying quality 
across state funded and private childcare centres, which are free to develop and follow their own programmes. In 2014, the government introduced free childcare for parents in full-time education or employment. There is a minimum regulatory framework binding child day care centres with a provisional registration certificate, and national standards of care services, which are not legally binding. Long hours of work that dominate Malta's organisational culture and the lack of adequate care provision affect women's labour market behaviour, and reinforce the need to scale down on working hours.

Women's share in Malta's employment rate in 2014 remains persistently low at 49.3 per cent compared with the EU-28 average of 59.6 per cent. In parallel, the gender employment gap stands at a high 25.6 percentage points, ranking highest among the EU28 and significantly higher than the EU-28 average (10.5 percentage points). Observation of statistical trends of women's age-related economic activity rates shows that in their prime years of working, women in Malta are forced to leave full-time employment owing to long working hours and inadequate provision of support mechanisms. For instance, Eurostat data show that the impact of parenthood in Malta in 2014 is 10 percentage points for women: in the age group twenty to forty-nine, the employment rate of non-mothers was 10 percentage points higher than that of women with children under seven years of age, an increase of 0.5 percentage points from 2013. By contrast, the impact of parenthood for men is $\mathbf{- 9 . 3}$ percentage points. While the employment impact for women in Malta is higher when compared to the EU-28 level (8.2 percentage points), the impact for Maltese men is lower than the European average (-12 week percentage points) (Eurostat, 2014). ${ }^{2}$

Rights to a shorter working week for parents of young children make time available; however, family-friendly policies in Malta are often drawn up with women in mind. For example, employees in Malta's public sector may apply to work reduced hours: between twenty and thirty-five hours a week and pro-rata payment, until the child is sixteen. However, reduced hours are largely taken up by mothers rather than by fathers, reinforcing a gender-divide in earnings and unpaid care work. For instance, women's share of reduced hours in 2014 was 93 per cent. In parallel, the take-up rate of parental leave was thirteen men and 473 women (PAHRO, 2014). Clearly, the male breadwinner model is embedded not only in Maltese culture and its social norms, but also in the state's own social policies (Camilleri-Cassar, 2015). The next sections discuss the methodological approach in the study, and emergent findings.

\section{A note on methodology}

The study asks about time, and engages with voices of a random purposive sample of thirty-nine women between the ages of twenty-eight and thirty-eight years, through indepth, face-to-face semi-structured interviews. The interviews allowed me to understand the present situation and existing complexities in the life of a group of Maltese women. Indeed, the article is organised around themes emerging in the voices of my study participants. Such a study required methods that allowed me to listen to women's words, while remaining alert to non-verbal communication. Further observational support was forthcoming from a research diary that kept a record of the various emotional, intellectual and logistic hurdles encountered along the way. Experience with diary entries reinforces their usefulness at the stage of data interpretation and analysis, along with the review of relevant documents that together enhanced an understanding of the phenomenon under study. 
I also elicited data through employing the 'hanging out' (Dingwall, 1997: 53) method, by visiting and interviewing my study participants in their 'natural surroundings' while about their daily activities (Kvale, 1996: 293). Observation in the respondents' own setting, whether at the workplace or at home, helped me understand women's relationships and the meanings attached to their experiences of Malta's working-time regime. For example, interviews carried out inside respondents' homes revealed the traditional gender arrangement within many Maltese families, where women had turned their backs on the labour market and were looking after their children, while husbands were out working or furthering their studies abroad.

This research adopts the key characteristic of a qualitative study in that it attempts to see through the eyes of the people studied. Essentially, if I were to adopt a quantitative mode of inquiry, associated with objectivity and statistics, would I hear my respondents express their feelings of frustration in Malta's male model of work? For example, would numbers have told me of Nikki's 'big shock!' during her unpaid parental leave, when she experienced financial dependence on her husband for the first time in her adult life? She says, 'I think that's the biggest shock, ending up not even having one cent which really belongs to me!' Would quantification have allowed me to hear Jade express that, 'an important part of me has died, the engineer part of me has died, and I feel really bad!' after she was compelled to give up full-time employment? Numbers talk to the extent that Jade would have been a statistic in the part-time workforce, and Nikki a number in the parental leave data table. Moreover, I could easily have interpreted Jade's part-time employment as a convenient option to a work-life balance, and Nikki's entitlement to parental leave, as reflecting a progressive welfare state with family-friendly measures. The reality is that both these voices draw strong implications for Malta's working-time regime and its social policy. In the contradictions women face, questions arise about Malta's claims to gender equality. I argue that there are aspects to women's lives that cannot be pre-known or predefined, as would be determined by a quantitative method of research. This study aims at giving women the voice they are often denied in everyday life. Other sources of information include relevant legislation, published state documents and national data sources used by government to help inform policy. Thus, the study's triangulation of sources ensures it is more than one-dimensional.

While there are limitations to purposive sampling (Berg, 2007; Silverman, 2001), its strengths lie in identifying respondents that meet a very specific set of criteria (Arber, 1993). The primary criteria for the sample were partnered heterosexual women, with dependent children, and a background of tertiary education. Arguably, graduate women present a strong test case for an exploration of the impact of Malta's working-time regime on mothers with dependent children: they are the better educated, have wider access to employment opportunities, may be more able to pay for childcare and would likely have had a clear career path in mind during their university days. I argue that if partnered university-educated women are facing difficulties, in terms of Malta's gender-work regime, then the situation of other groups of women is likely to be worse. However, this would necessitate further research. Additionally, as Malta's work-life measures are presented as family-friendly, I wanted to understand through women's voices, the extent to which husbands share familial responsibilities. For instance, Warren et al. (2010) argue that in heterosexual-couple households, mothers tend to experience pressure on time, and their ability to work, care and manage households. This is supported by Eurostat data, which demonstrate the impact of parenthood in Malta, as discussed earlier in the article. 
Another reason for selecting a sample of tertiary educated women draws on the outcome of various tracer surveys undertaken by the University of Malta. The findings always seem to suggest that despite the creation of a large reservoir of educated women, Malta's culture of long working hours is a major obstacle to their career aspirations, and the major reason for labour market exit when they have children. Other family types are not included in this research, which necessarily restricts the conclusions of my study. Nevertheless, the special characteristic of a highly educated study population, in their prime working age, makes the sample in this study quite unique.

Fieldwork was carried out between December 2012 and September 2013. The respondents come from diverse socio-economic backgrounds, and there is no distinction between urban and non-urban in Malta's small population. During the time of the study, seven of the study respondents had already exited the labour market due to familial obligations.

Full transcription of data from audio tape recordings followed the completion of each interview. The transcripts are rich in data and include pauses, emphases and changes in voice tone, laughter and interruptions. A research diary stored personal experiences, ideas and responses to situations that occurred along the data collection journey. After each interview, I noted location of encounter, length of time, attitude of respondent, interruptions and any subtle messages that came my way during fieldwork. Audio recordings were heard several times over, and field notes and diary entries were read and re-read for a clearer understanding of concepts and themes. 'Rambling' was also documented, as it provides an insight into women's ways of interpreting and making sense of the gender arrangement in Malta's working-time regime. I devised a system where data were categorised into main themes and sub-themes, throughout all transcripts. This was done manually, as I wanted to remain close to my data by highlighting key substantive dimensions.

I then grouped the transcripts according to respondents' status, so as to sharpen accounts, understand detail from different perspectives and experiences, and ultimately for interpretation. Thus, 'the combination of interviews and observations from the field, along with reviews of relevant documents increases the likelihood that the phenomenon of interest is being understood from various points of view and ways of knowing. Convergence of a major theme or pattern in the data from interviews, observations and documents lends strong credibility to the findings' (Maykut and Morehouse, 1997: 146).

In order to understand the complexities of women's lives, I adopted Strauss and Corbin's (1990) approach of 'accurate description'. Accurate description of data is interspersed with my own interpretive comments that draw on policy literature, Maltese legislation, diary entries and especially verbatim quotes drawn from women. Official indicators and other sources of information lent support and validity to the development of analysis and interpretation of data. Verbatim quotes ensured loyalty to concerns entrusted to me by my respondents. Indeed, data quotes may give audiences a free hand for alternative interpretation.

Finally, although I do not classify my sample population as a vulnerable group, such as one that relates to serious social problems, the study necessitated the informed consent principle, wherein the research agenda was explicit: on the telephone when I first called for an appointment, and then again at the outset of each interview. The identity of respondents is protected, and names are replaced by pseudonyms of their own choice. 


\section{Career or family?}

Largely overlooked in national studies is Malta's culture of long working hours, and its implications for women's ability to combine work and family. For instance, how much do state policies in Malta assume that men and women both need time for care, as well as for paid work? The majority of participants in this study have had to adjust their fulltime working hours to suit family needs. Alternative work arrangements meant a move to self-employment with flexible and shorter than full-time working hours, or a change in career to teaching with working hours compatible with their children's school hours. Very short part-time hours were also an option for some women, however, for others unable to secure convenient working time arrangements, full-time housewife was the next best thing. Implicit in the responses is an understanding that men's time is valued more, as the study finds a general tendency among respondents to put their husband's career first.

For example, while Clara accommodates family needs by shifting career from senior pharmacist to schoolteacher, her husband seems undeterred by family commitments. Clara says that he works long hours on a daily basis because besides his full-time job, he also works part-time. How does Clara feel about the change in her career?

I changed over to a teacher ... I'm not happy ... it's not something sort of . . I mean, you feel it imposed ... my salary scale too has gone down ... but then you say family comes first ... I mean, it was either me or my husband ... emm ... it's something we discussed you know ... and I felt I should be the one to do it ... if it wasn't because of the children I think I'm still a pharmacist. (Clara, senior pharmacist switched career to school teacher)

The difference in hours worked by the study respondents and their full-time working husbands reflect women's greater involvement in the domestic sphere. This difference is supported by the gender gap in Malta's parent impact rate discussed earlier in the article. Walby (1997) suggests that women's decisions on the division of time between paid and unpaid work are made within the options open to them. 'But those choices cannot be understood outside of an understanding of the development of the institutions and structures which construct those options' (Walby, 1997: 25). Rose was employed fulltime as an electrical engineer, and was moving steadily up the career ladder. However, she is now out of the labour market. She argues that her family takes priority of her time:

I used to work long hours ... well, normal hours really but too long for family commitments ... I mean, from eight until five straight ... we had a lot of work and were often forced to stay overtime ... I had many conflicts with the manager because I used to want to go home ... I can't imagine myself returning to such a situation ... spending more time at work than at home ... obviously, I would have to neglect the family. (Rose, electrical engineer switched career to full-time housewife)

Buswell and Jenkins (1994) point out that the masculine features of time-use are very long working hours, and the expectation that every other aspect in life be of secondary importance. Martina's husband works long hours. She is aware of the skewed division of time devoted to domestic work, but makes excuses for her husband. She rationalises that the imbalance in unpaid care work is justified:

Last week I didn't go to work 'cause she was in the hospital (pointing to child) ... I was the one to stay in the hospital and my husband was going to work ... nothing much you can do ... he has a lot of people working for him in his Company ... I have none ... so it was easier 
for me, so I stayed ... anyway, I'm easier with her, you know what I mean? ... he's clumsy with feeds and everything ... so, it was only natural that I stayed with her ... (Martina, legal procurator switched to self-employment)

The verbatim quotes seem to suggest that when women adopt the traditional gender arrangement of care responsibilities, time is made available to men at the cost of women's own time. Indeed, 'women make choices, but not under conditions of their own making [and] choose the best option that they can see' (Walby, 1997: 25). Conformity to traditional gender norms and men's fragile commitment to their family seem to be taken as the natural order of things, rather than a constraint for women in Malta.

Jade speaks with strong emotion during the interview. She loves her work in electrical engineering, but had to shift to part-time hours. What is Jade's experience of her newly acquired twelve-hour-a-week job?

I lost my seniority ... I lost a lot on technology ... technology advances, because although I tried my best to keep up, you can never keep up ... it's very hard with two children ... and also, I could have gained much more training and insight and everything. Now, I have to catch up ... so I have to start working again plus catch up with what I lost in these three and a half years and emm ... OK, I have a good CV ... I have a good background and good experience $\ldots$ but that $\mathrm{CV}$ is not me any more ... I mean, I'm also feeling very uncomfortable in front of a keyboard and PC which were for me like using a pencil ... I was an IT manager, so they are treating me as an IT manager, as if there was never this break ... they won't appreciate it ... they don't understand that I have to get acquainted with even a keyboard, report writing, anything basic, so to speak. (Jade, electrical engineer switched to part-time)

\section{What changes in employment conditions would enable study respondents to go back to full-time work?}

Within the context of women's working time in the Maltese labour market, I asked respondents what employment conditions would enable them to go back full time work with the following question: 'If an organization really wanted you, what would they need to do to bring you back full time?' To clarify further, I pose the following scenario: 'Imagine that you receive a telephone call, right now as we talk, asking you to return to work full time, with conditions of employment determined by yourself. What changes would you ask for?'

At the moment I won't go ... I won't go for sure ... the hours ... mostly the hours ... I can't have full-time hours from 8 until 5 ... it's impossible, you know? ... maybe, I would ask to do some work here at home with the child ... but, right now as things are, you know? Emm ... that's all I can say ... (Maya, lawyer switched career to full-time housewife)

Annie a medical doctor is on parental leave, which is unpaid in Malta's social welfare system. Unlike her husband who is also a medical doctor, Annie has had to interrupt her career twice in seven years because of her children, and she discloses that, 'resigning from work is hard'.

When I worked in the casualty department full time, for the number of hours I worked and the stress I endured, the money was not such a big deal ... but it's not just the money you know? ... I would need a lot of flexibility... I think that is what I would ask for mostly, flexibility. (Annie, medical doctor switched to casual part-time) 
While working full-time for a law firm, Angela reluctantly resigns, because 'obviously, when you have children you can't be out of the house for such a long period of time'. She now works what she calls a 'decent 20-hour week'. Angela provides flexibility to her own working hours by shifting from full-time employment to flexible self-employment. What changes would enable Angela to go back to working full-time?

I think basically flexible hours ... it would be very convenient to have that 'cause then you can work around your family ... (Angela, lawyer switched career to part time self-employment)

Intermittent employment due to Malta's long-hours working-time regime is a significant finding in this study. For example, Hannah has interrupted her career for the second time, and her working hours fell from thirty to ten hours per week. Typical of Malta's traditional gender arrangement, while her husband is furthering his studies abroad, Hannah does odd jobs as an accountant. Why is Hannah and her husband's allocation of time so diverse? If an auditing firm really wanted Hannah, what would it need to do to bring her back to a full-time working commitment? The response reflects entrenched cultural assumptions about Malta's traditional gender roles, and raises questions about the effectiveness of Malta's policies for reconciling work and family. Hannah says:

the concept of flexitime which in my case was granted for a while ... I could work from home and go to my office ... but you can't work from home all the time ... you have to go over there sort of ... flexitime would be ideal. (Hannah, accountant switched career to part-time)

\section{Negotiating time and the domestic division of labour}

The study respondents seem concerned about the difficulties in juggling time. Walby (1999: 7) suggests that 'such long hours militate against men doing their share of care'. In terms of negotiating time with their husbands, I ask the study participants the following: 'Did you discuss domestic chores and employment before you got married?' Fourteen women claim they discussed expectations of both paid and unpaid work; two interviewees discussed employment but not household chores, as these were assumed to be women's responsibility; twenty-three respondents said that they had none of these discussions, and had allowed Malta's traditional gender arrangements to fall into place. However, women's accounts seem to suggest a complacent attitude towards a gender model that infringes on their time, and that 'gives men a collective advantage over women in the public sphere' (Lister, 2003a, 2003b).

For example, Marisa seems accepting of the gender imbalance at home. Had she discussed domestic tasks and employment before she got married?

No, no ... we never discussed these issues ... his work is more demanding than mine ... so obviously, I have more time to spare and I do the housework automatically ... there was a time when he also worked part time so it's difficult for him ... (Marisa, mechanical engineer switched career to school teacher)

Gershuny (2000: 56) suggests 'it is male power, rather than female inclinations, that determines that women's labour is and should be concentrated in household maintenance and reproductive functions'. For example, throughout the interview, Rose describes her 
husband's understanding of house chores, and presents herself as happy to accommodate his wishes. Were domestic chores and employment a point of discussion between Rose and her husband, prior to their marriage?

Yes, we had discussed both ... domestic tasks and employment ... emm ... before we got married we decided that as soon as we have children I stop work ... and he also always told me that he hates housework (laughs) ... so nothing came as a surprise ... (Rose, electrical engineer switched career to full-time housewife)

Like notions of women as a reserve labour force, men view women's paid work as something that can ebb and flow depending on family needs (Gerson, 2013). For instance, did Sophie and her husband discuss domestic chores and employment before they got married?

No, no, no ... not really ... I don't have the type of husband who would ... he already had these fixed ideas about women, so I don't discuss things when I know ... that would be messing up with the system ... (Sophie, full-time university lecturer)

Gershuny (2000: 56) suggests that 'the 'gender ideologies' of both sexes embody some version of the 'happy housewives' view, which serves to inhibit change in couples' behaviour'. Daniela illustrates this point in her response:

Employment we discussed ... domestic chores no ... I never expected him to wash my floors, for example ... I don't think I would let him because I get things done quicker ... as long as I can cope there's no need ... if I'm with my back to the wall, yes ... (Daniela, full-time teacher)

Creighton (1999) states: 'While it is widely recognized that men's long hours of work are a major impediment to their assuming more domestic responsibilities, there is of course no guarantee that they would use their additional non-working hours for domestic tasks; much depends upon the prevailing cultural climate' (p. 534). Buswell and Jenkins (1994: 89) argue that 'men can only give more time to their jobs if they do less at home, and thus prove their masculinity and loyalty to the company; as their pay increases so does their exemption in the domestic sphere'. Relatedly, Walby (1997) adds that time is as much an issue as money; however, since only employment is routinely accounted for in monetary terms, women's unpaid time can easily be hidden from view.

\section{Role reversal: challenging a traditional gender arrangement?}

Most study respondents clearly reveal a perception that men are, above all, workers and breadwinners who could not be expected to stay at home. Regardless of traditional expectations, I asked study participants, 'would you consider your husband staying at home, while you work full time?' Most respondents reacted with a laugh. What are the obstacles that may slow down the process of transition from a traditional gendered regime to an equal sharing of time?

No! First of all he earns more than me ... he has a better pay ... secondly, he doesn't know how to do anything (laughs) he can't cook! ... (Marisa, mechanical engineer switched career to school teacher) 
Would Martina consider working full-time while her husband stayed at home to look after the children?

No, no, no, no, no! ... I know how he is ... and even if I was better paid ... definitely he won't ... he runs a business ... it's different ... his job is more important than mine ... at the end of the day, if one of us had to sacrifice the work, it would be me not him ... (Martina, legal procurator switched to self-employment)

The voices of my study respondents clearly demonstrate Malta's attitudinal traditionalism and women's adherence to societal ideals and notions by supporting, and indeed reinforcing the 'appropriate' gender division of labour.

\section{Conclusion}

The study asks about time. It engages with the concept of working-time regimes and develops an understanding of time allocation and Malta's culture of long working hours in wage labour. To what extent is Malta's traditional gender arrangement challenged by its working-time regime? Rubery et al. (1998: 71) suggest that, 'progress towards equal opportunities is critically dependent upon the development of a more equal and more balanced allocation of time, in both paid and unpaid work'. Recent literature adds that the distribution of time, work and resources within households is central to gender equality (Pascall, 2012). Indeed, how effective are Malta's policies in promoting gender equality in time for care and paid work? To what extent has Malta's social policy succeeded in its objective to promote the equal status of women through a balanced share of time?

The findings of this study suggest a significant gender divide in hours used for earning and unpaid care work. Women are constrained by their husband's employment and the assumed priority they have in this respect. This study further suggests that the burden of care giving and the state's limited involvement in supporting working parents, impinge on women's hours of paid work. Eurostat data on the impact of parenthood in Malta and rates of employment support the findings of this study.

The voices in this research show that women accept men's minimal involvement in care work, and also place a higher value on men's time than their own. For instance, Martina says, 'it's only natural that I take care of the children' and 'it's easier for me to stay at home while he goes out to work'. The respondents' response to a hypothetical scenario of a gender role reversal reflects a conservative family culture and women's deeply ingrained sense of obligation. Indeed, gendered time that compels women to reduce their hours of earning contributes to Malta's level of understanding of its working-time regime. Respondents accommodate care work by shifting career or exiting the labour market. In parallel, men seem to dedicate most of their time to paid work and career advancement.

Pascall and Lewis (2004) suggest that unequal working hours between women and men are a key reason for the failure of gender equality policies. Indeed, a key concern shared by most women in the study is career regression due to intermittent work. Standard paid work in Malta entails long hours. Shorter hours and career breaks are often interpreted as lack of labour market commitment.

I conclude that the gendered division of time in Malta points to a single earner regime, with very little adaptation from the traditional gender arrangement. Rather than an equal distribution of time for paid and unpaid work between women and men, the study 
findings suggest that gender equality in Malta is conceived in terms of accommodating men at the expense of women's own time. There appears to be a deeply ingrained set of cultural assumptions and obligations within the family, which structure workplace expectations, and which thus make it difficult for women to juggle both paid and unpaid work. Furthermore, these expectations spill over into relationships within the bureaucracy, such that government policies are blunted in their effect. Social policy dialogues in Malta must give way to a paradigm shift in the historically unequal power relations between women and men. 'Rather than accepting the accommodation of working time to the gendered division of labour, policies that change the male model of full-time employment could provide an institutional basis for the reallocation of reproductive labour within the household' (Figart and Mutari, 1998: 462). Moreover, contradictions and limitations underpinning state policies must be identified and resolved.

Perhaps, shorter working hours would begin to address time inequalities? An inescapable implication for Maltese social policy is that the state's key source of failure in achieving gender equality is its resistance to address cultural and structural disadvantages for women in its work-time regime. 'A much shorter working week would ... re-shape habits and conventions, and profoundly alter the dominant cultures of western society' (Coote et al., 2010: 25). Indeed, the study makes an argument for the right to time, and a reduction in working hours for both women and men. It also argues for policies and legal measures, backed by appropriate legislative support, to ensure that limits on working time in Malta are strictly enforced.

\section{Notes}

1 See LN 247 of 2003 Organisation of Working Time Regulations.

2 The employment rate of non-mothers was 8.1 percentage points higher than that of women with children under the age of seven years.

\section{References}

Arber, S. (1993) 'Designing samples', in N. Gilbert (ed.), Researching Social Life, London: Sage, 68-93. Baldacchino, G. (2009) Trade Unions in Malta, Report 110, Brussels: European Trade Union Institute, aisbl.

Berg, B. L. (2007) Qualitative Research Methods for the Social Sciences, Boston, MA: Pearson.

Buswell, C. and Jenkins, S. (1994) 'Equal opportunities policies, employment and patriarchy', Gender, Work and Organization, 1, 2 (April).

Camilleri-Cassar, F. (2015) 'Country fiche on gender equality and policy developments (4th quarter), External report commissioned by and presented to the EU Directorate-General Justice, Unit G1 'Equality between women and men'.

Coote, A., Franklin, J. and Simms, A. (2010) 21 Hours: Why a Shorter Working Week Can Help Us All to Flourish in the Twenty-First Century, London: New Economics Foundation.

Creighton, C. (1999) 'The rise and decline of the male breadwinner family in Britain', Cambridge Journal of Economics, 23, 519-41.

Dingwall, R. (1997) 'Accounts, interviews and observations', in G. Miller and R. Dingwall (eds.), Context and Method in Qualitative Research, London: Sage, 51-65.

Eurofound (2012a) Trends in Job Quality in Europe, Luxembourg: Publications Office of the European Union.

Eurofound (2012b) Working Time and Work-Life Balance in a Life Course Perspective, Dublin: Eurofound. Eurostat (2014) Labour Force Survey, http://ec.europa.eu/eurostat [accessed 10.01.2015]. 
Fagan, C. and Burchell, B. (2002) Gender, Jobs and Working Conditions in the European Union, European Foundation for the Improvement of Living and Working Conditions, Luxembourg: Office for Official Publications of the European Communities.

Fagan, C. and Warren, T. (2001) Gender, Employment and Working Time Preferences in Europe, European Foundation for the Improvement of Living and Working Conditions, Luxembourg: Office for the Official Publications of the European Communities.

Fagnani, J. and Letablier, M. T. (2006) 'The French 35-hour working law and the work-life balance of parents: friend or foe?', in D. Perrons, C. Fagan, L. McDowell, K. Ray and K. Ward (eds.), Gender Divisions and Working Time in the New Economy, Cheltenham: Edward Elgar, 79-90.

Figart, D.M. and Mutari, E. (1998) 'Degendering work time in comparative perspective: alternative policy frameworks', Review of Social Economy, 56, 4, 460-80.

Figart, E. and Mutari, D. (2000) 'Working time regimes in Europe: can flexibility and gender equity coexist?' Journal of Economic Issues, 34, 4, 847-71.

Fox, E., Pascall, G. and Warren, T. (2006) Innovative Social Policies for Gender Equality at Work, The University of Nottingham and European Social Fund.

Gerson, K. (2013) 'Men's resistance to equal sharing', in M. S. Kimmel (ed.), Men's Lives, 9th edn, New York: Pearson Education, 332-52.

Gershuny, J. (2000) Changing Times: Work and Leisure in Postindustrial Society, Oxford: Oxford University Press.

Jacobs, J. A. and Gerson, K. (2004) The Time Divide: Work, Family, and Gender Inequality, Cambrdige, MA: Harvard University Press.

Kvale, S. (1996) Interviews: An Introduction to Qualitative Research Interviewing, Part IV, Sage Publications, 277-98.

Lehndorff, S., Bosch, G. and Rubery, J. (2007) 'European employment models under pressure to change', International Labour Review, 146, 253-77.

Lister, R. (2003a) Citizenship: Feminist Perspectives, 2nd edn, Basingstoke: Palgrave Macmillan.

Lister, R. (2003b) 'Principles of welfare', in P. Alcock, A. Erskine and M. May (eds.), The Student's Companion to Social Policy, 2nd edn, Oxford: Blackwell, 260-66.

Maykut, P. and Morehouse, R. (1997) Beginning Qualitative Research: A Philosophic and Practical Guide, London: The Falmer Press.

PAHRO (2014) Family Friendly Measures Report, Malta: Public Administration HR Office.

Pascall, G. (2012) Gender Equality in the Welfare State? Bristol: Policy Press.

Pascall, G. and Lewis, J. (2004) 'Emerging gender regimes and policies for gender equality in a wider Europe', Journal of Social Policy, 33, 3, 373-94.

Pillinger, J. (2000) 'Redefining work and welfare in Europe: new perspectives on work, welfare and time', in G. Lewis, S. Gewirtz and J. Clarke (eds.), Rethinking Social Policy, London: Sage, $323-37$.

Plantenga, J. (2002) 'Combining work and care in the polder model: an assessment of the Dutch part-time strategy', Critical Social Policy, 22, 1, 53-71.

Plantenga, J. and Hansen, J. (2001) 'Assessing equal opportunities in the European Union', in M. Fetherolf Loutfi (ed.), What Is Equality and How Do We Get There? Women, Gender and Work, Geneva: International Labour Office, 273-304.

Rubery, J., Smith, M. and Fagan, C. (1998) 'National working-time regimes and equal opportunities', Feminist Economics, 4, 1, 71-101.

Silverman, D. (2001) Interpreting Qualitative Data, London: Sage.

Sollars, V., Attard, M., Borg, C. and Craus, B. (2006) Early Childhood Education and Care: A National Policy, Malta: Ministry of Education, Youth and Employment.

Strauss, A. and Corbin, J. (1990) Basics of Qualitative Research: Grounded Theory Procedures and Techniques, London: Sage.

Walby, S (1997) Gender Transformations, Abingdon: Routledge. 
Walby, S. (1999) 'Introduction', in S. Walby (ed.), New Agendas for Women, Macmillan Press Ltd/St Martin's Press, Inc., 1-16.

Warren, T. (2000) 'Diverse breadwinner models: a couple-based analysis of gendered working time in Britain and Denmark', Journal of European Social Policy, 10, 4, 349-71.

Warren, T, Pascall, G. and Fox, E. (2010) 'Gender equality in time: low-paid mothers' paid and unpaid work in the UK', Feminist Economics, 16, 3, 193-220.

Warren, T. (2014) 'Economic crisis, work-life balance and class', Social Policy Review, 26, 11-28.

Zbyszewska, A. (2013) 'The European Union Working Time Directive: securing minimum standards, with gendered consequences', Women's Studies International Forum, 39, 30-41. 